\title{
Outcome of pedicle screw fixation with transpedicular bone grafting in fracture of thoracolumbar vertebrae
}

\author{
Harpreet Singh, Aliasgar J. Rampurwala*, Tej S. Rudani, Malay P. Gandhi
}

Department of Orthopaedics, Geetanjali Medical College and Hospital, Udaipur, Rajasthan, India

Received: 14 February 2020

Revised: 02 April 2020

Accepted: 06 April 2020

*Correspondence:

Dr. Aliasgar J. Rampurwala,

E-mail: draliasgar90@gmail.com

Copyright: (C) the author(s), publisher and licensee Medip Academy. This is an open-access article distributed under the terms of the Creative Commons Attribution Non-Commercial License, which permits unrestricted non-commercial use, distribution, and reproduction in any medium, provided the original work is properly cited.

\begin{abstract}
Background: Posterior short segment instrumentation for thoracolumbar fracture is known for high implant failure rate because of the lack of anterior support. Anterior body augmentation by transpedicular bone grafting has been developed as an alternative to overcome this failure. In this study, we have evaluated the outcome of the cases of the unstable thoracolumbar spine injuries managed surgically with pedicle screws and transpedicular bone grafting.

Methods: 20 patients were included in this study and were followed up for up to 6 months postoperatively. We assessed the outcome of each patient with Frankel scale and visual analog score (VAS) post-operatively clinically and radio logically by measuring Cobb's angle and anterior vertebral body height post-operatively on follow-up at 6 weeks, 12 weeks, and 24 weeks.

Results: We found that males had higher incidence with most common mode of injury was fall from height. D12 was single most involved vertebrae. The average Cobb's angle during preoperative stage was 12 degrees and 22.05 degrees at 6th week and this was maintained till 24th week. The mean difference of anterior vertebral body height between preoperative and 24th post-operative week was $7.15 \mathrm{~mm}$. The mean VAS pre-operatively was 9.8 which changed to 0.75 at 24 weeks follow up. These were statistically highly significant.

Conclusions: Our study established that Pedicle screw fixation with transpedicular bone grafting has a satisfactory result and can restore vertebral height, increase the stability of the injured vertebrae and leads to a significant improvement in the patient's quality of life.
\end{abstract}

Keywords: Transpedicular bone grafting, Pedicle screw fixation, Thoracolumbar fracture

\section{INTRODUCTION}

Spinal column injuries represent approximately $3 \%$ of all trauma case and $10 \%$ of spine injuries. ${ }^{1}$ Axial load on spinal column after trauma may result in incomplete or complete burst fractures which cause displacement of middle column into vertebral canal and can cause neural injury. The combination of an axially directed central compressive force with an eccentric compressive force anterior to the axis of rotation typically leads to wedge compression fractures. ${ }^{2}$ The trauma of thoracolumbar segment is high in thoracolumbar junction to the extent up to $60 \%$ between T12 to L2. Only $15-20 \%$ of the fractures at thoracolumbar level are associated with neurological injury. ${ }^{3-5}$ The goal of treatment of every spinal injury is the restoration of the patient's maximum possible function with a disability free life. Operative intervention is intended to convey immediate stability to the spine, allow for the correction of deformities, and optimize neurologic improvement by directly or indirectly relieving any residual impingement of the neural elements. ${ }^{6}$ Posterior pedicle screw fixation is most widely used for thoracolumbar fracture which can provide immediate spinal stability, improved correction of kyphotic 
deformities, early painless mobilization and indirect decompression of the spinal canal. ${ }^{7,8}$ Posterior short segment instrumentation for thoracolumbar fracture is known for high implant failure rate because of the lack of anterior support. Anterior body augmentation by transpedicular bone grafting has been developed as an alternative to overcome this failure. ${ }^{8}$ In this study, our aim was to determine the outcome of pedicle screw fixation with transpedicular bone grafting in injured vertebrae for the treatment of thoracolumbar fractures both clinically and radio logically and to study the adverse events/complication during intraoperative/post-operative of the procedure.

\section{METHODS}

This was a prospective, clinico-radiological, descriptive, observational, analytical study conducted from January 2018 to June 2019 in Geetanjali Medical College and Hospital at Udaipur, Rajasthan, India. Patients who met with the inclusion criteria were included in the study after scrutinizing them for any exclusion criteria. Patients with thoracolumbar vertebrae fracture diagnosed with X-ray and MRI, and classify according to Arbeitsgemeinschaft fur Osteosynthesefragen (AO) classification, and treated with pedicle screw fixation and transpedicular bone grafting were included in this study after obtaining their informed, valid written consent. We excluded any patients with any fracture of cervical vertebrae, any fracture of sacrum, with progressive neurological disease or pre injury neurological deficit, fracture of vertebrae at multiple levels, fractures manageable with conservative treatment and concomitant fracture of the lower limbs.

20 patients were included in this study and were followed up for up to 24 weeks post-operatively. After adequate preoperative (pre-operative) preparations, patient was taken for surgery electively. All these patients were operated by the same senior orthopedic surgeon. We performed Pedicle screw fixation with Transpedicular bone grafting in patients presenting with thoracolumbar fractures.

\section{Surgical procedure}

All procedures were performed under controlled general anesthesia in the prone position. A midline skin incision was made, and subcutaneous flaps were elevated bilaterally. We bluntly dissected muscles and placed selfretaining retractors, then exposed part of the facet joint. The pedicle screws were implanted in the one level above and lower vertebrae of injured vertebrae.

Fixation was achieved through connecting rods, producing distraction. The bone which received from removed lamina and pedicle was reduced to particles and injected into the injured vertebrae through pushrod. After wound irrigation closure was done in layers. Aseptic dressing was done.

\section{Postoperative management}

Mobilization of the lower limbs was started from first day post operatively. On the second day patients were allowed to roll from side to side. They were allowed to sit up with support and were mobilized on a wheel chair after application of thoracolumbar belt on third or fourth postoperative day. Patients wore thoracolumbar belt for about 6 weeks. Those with incomplete neurological deficits were given lower limbs active assisted exercises and gradually ambulated. Patients with complete neurological deficits were given lower limbs passive assisted exercises and ambulated on wheel chair.

We assessed the outcome clinically of each patient with Frankel scale and VAS (visual analog score) and radio logically by measuring Cobb's angle and anterior vertebral body height (AVBH) on follow-up at 6 weeks, 12 weeks and 24 weeks. ${ }^{9,10}$ We recorded the change in Frankel scale and VAS score clinically and radio logically by measuring Cobb's angle and anterior vertebral body height between pre-operative and post-operative at each follow up. We also studied the adverse events/complication during intraoperative/post $\mathrm{W}$ operative of the procedure.

\section{RESULTS}

Of 20 patients, 16 were males and 4 females (Figure 1) with mean age of 34.7 years and standard deviation of 14.77 years. The most common age group in our study was 21-40 years. The most common mode of injury in our patient was fall from height followed by Road traffic accident and fall of heavy object (Figure 2). The most common vertebral level affected was D12 followed by L1, L2, and L3 (Figure 3). Most common fracture type was A3 (Figure 4).

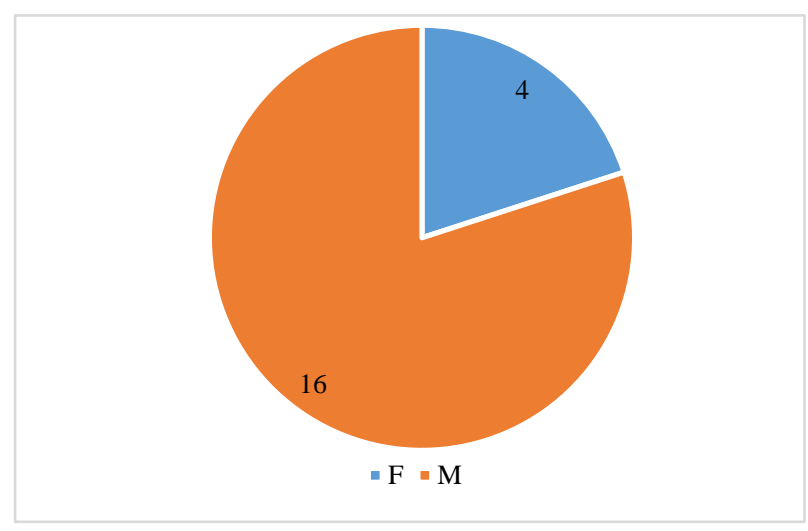

Figure 1: Sex distribution.

\section{Pre- and post-operative Frankel scale}

The most common type of Frankel scale baseline (preoperative) was $\mathrm{E}$, seen in 7 patients who had no neurological deficit. At 6 weeks, 8 patients had no neurological deficit (Frankel scale= E). At 12 weeks, 11 patients had no neurological deficit (Frankel scale= E). At 
24 weeks, 13 patients had no neurological deficit (Frankel scale $=\mathrm{E})$.

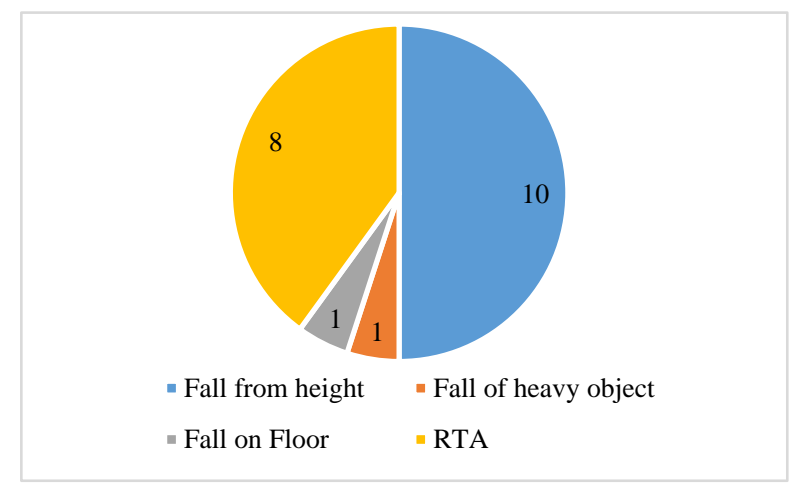

Figure 2: Mode of injury.

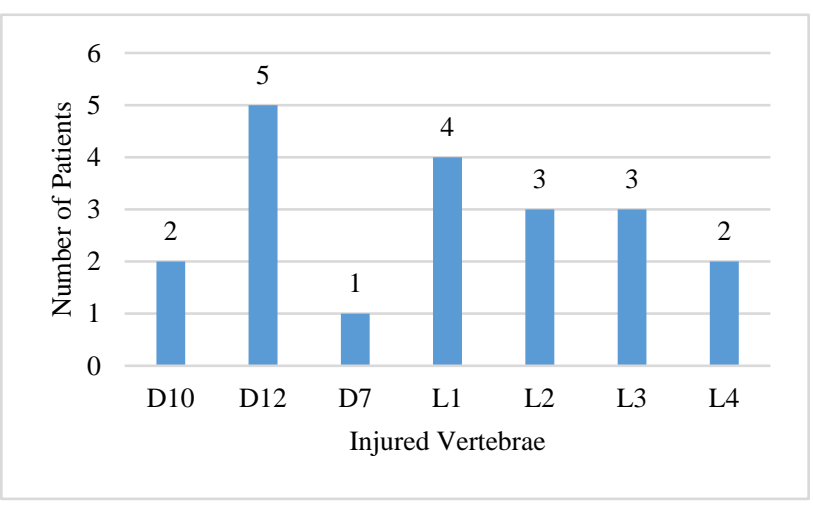

Figure 3: Vertebral level affected.

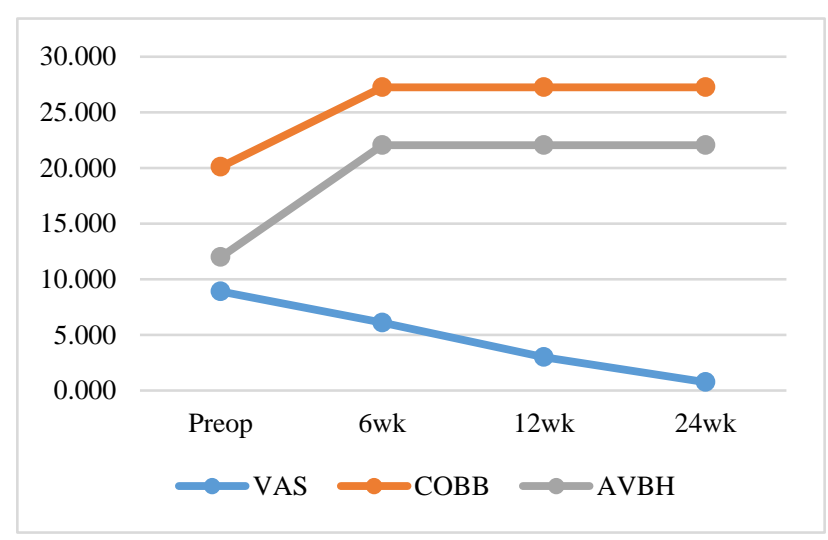

Figure 5: Scores.

\section{Pre and post-operative $\mathrm{VAS}$}

The mean value of the VAS at baseline was 9.8, which decreases significantly to 6.8 at 6 weeks, and the decline was continuously seen at 12 weeks with value of VAS score to 3 and at $24^{\text {th }}$ weeks mean VAS score decreased to a very low level of 0.75 (Figure 5).The scores on each follow up were compared to the pre-operative score using dependent 'paired t' test and the decrease in VAS was found to be statistically highly significant $(\mathrm{p}<0.001)$ (Table 1).

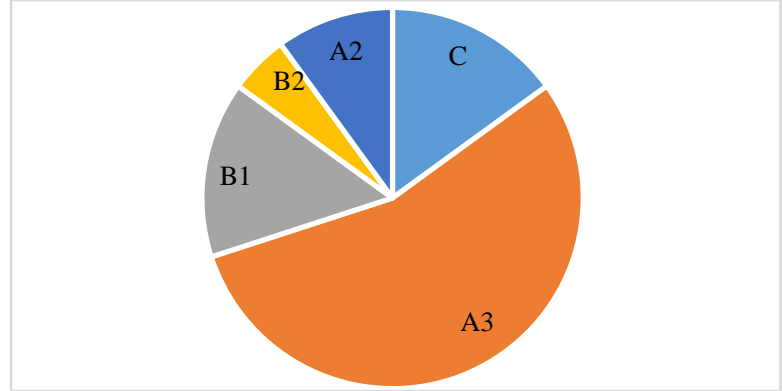

Figure 4: Type AO.

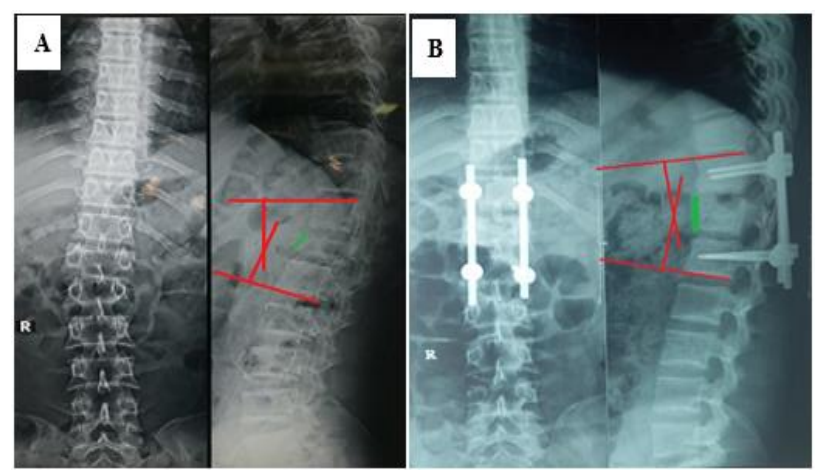

Figure 6: (A) Pre-operative radiograph of 30 years old male patient D12 \# and (B) post-operative radiograph after 24 weeks.

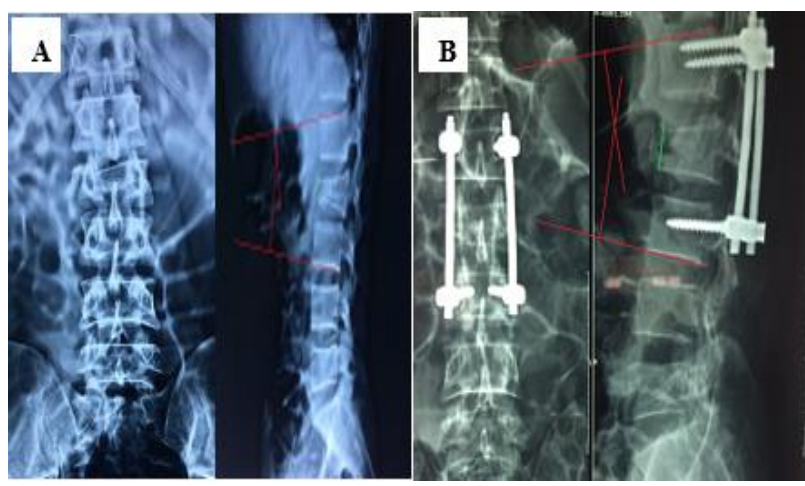

Figure 7: (A) Pre-operative radiograph of 25 years old male patient L2\# and (B) post-operative radiograph after 24 weeks.

\section{Pre- and post-operative Cobb's angle}

Cobb's angle was improved significantly from the mean value of 12 degrees preoperatively to 22.05 degrees at $6^{\text {th }}$ week and this was maintained till $24^{\text {th }}$ weeks (Figure 5). This change in Cobb's angle was found to be highly significant with fractures of the lumbar vertebra (Table 2).

\section{Pre- and post-operative $A \mathrm{VBH}$}

The mean anterior vertebral body height was seen to improve from baseline value of $20.1 \mathrm{~mm}$ preoperatively to $27.25 \mathrm{~mm}$ at $6^{\text {th }}$ week and this improvement persisted till $24^{\text {th }}$ weeks (Figure 5). 
Table 1: Difference between the scores at difference intervals.

\begin{tabular}{|c|c|c|c|c|}
\hline Variables & Mean & Std. deviation & Std. error mean & Significance \\
\hline VAS pre-operative & 9.800 & 0.4104 & 0.0918 & \multirow{2}{*}{0.000} \\
\hline VAS 6 weeks & 6.800 & 0.9514 & 0.2127 & \\
\hline VAS pre-operative & 9.800 & 0.4104 & 0.0918 & \multirow{2}{*}{0.000} \\
\hline VAS 12 weeks & 3.000 & 1.4142 & 0.3162 & \\
\hline VAS pre-operative & 9.800 & 0.4104 & 0.0918 & \multirow{2}{*}{0.00} \\
\hline VAS 24 weeks & 0.750 & 0.7864 & 0.1758 & \\
\hline COBB'S pre-operative & 20.100 & 3.9987 & 0.8941 & \multirow{2}{*}{0.000} \\
\hline COBB'S 6 weeks & 27.250 & 3.9454 & 0.8822 & \\
\hline COBB'S pre-operative & 20.100 & 3.9987 & 0.8941 & \multirow{2}{*}{0.000} \\
\hline COBB'S 12 weeks & 27.250 & 3.9454 & 0.8822 & \\
\hline COBB'S pre-operative & 20.100 & 3.9987 & 0.8941 & \multirow{2}{*}{0.000} \\
\hline COBB'S 24 weeks & 27.250 & 3.9454 & 0.8822 & \\
\hline AVBH pre-operative & 12.000 & 2.0774 & 0.4645 & \multirow{2}{*}{0.000} \\
\hline AVBH 6 weeks & 22.050 & 2.4165 & 0.5403 & \\
\hline AVBH pre-operative & 12.000 & 2.0774 & 0.4645 & \multirow{2}{*}{0.000} \\
\hline AVBH 12 weeks & 22.050 & 2.4165 & 0.5403 & \\
\hline AVBH pre-operative & 12.000 & 2.0774 & 0.4645 & \multirow{2}{*}{0.000} \\
\hline AVBH 24 weeks & 22.050 & 2.4165 & 0.5403 & \\
\hline
\end{tabular}

Table 2: Change in Cobb's angle at different intervals according to vertebral level.

\begin{tabular}{|c|c|c|c|c|c|c|c|}
\hline \multicolumn{2}{|c|}{ Variables } & \multirow{2}{*}{$\begin{array}{l}\text { No. of } \\
\text { patients } \\
2\end{array}$} & \multirow{2}{*}{$\begin{array}{l}\text { Cobb's } \\
\text { pre-operative } \\
22.000\end{array}$} & \multirow{2}{*}{$\begin{array}{l}\text { Cobb's } \\
6 \text { weeks } \\
28.500\end{array}$} & \multirow{2}{*}{$\begin{array}{l}\text { Cobb's } \\
12 \text { weeks } \\
28.500\end{array}$} & \multirow{2}{*}{$\begin{array}{l}\text { Cobb's } \\
24 \text { weeks } \\
28.500\end{array}$} & \multirow{3}{*}{$\begin{array}{l}\text { P value } \\
0.1920\end{array}$} \\
\hline D10 & Mean & & & & & & \\
\hline & Std. deviation & & 4.2426 & 2.1213 & 2.1213 & 2.1213 & \\
\hline \multirow[t]{2}{*}{ D12 } & Mean & 5 & 21.600 & 28.200 & 28.200 & 28.200 & \multirow{2}{*}{0.0808} \\
\hline & Std. deviation & & 5.5045 & 6.0581 & 6.0581 & 6.0581 & \\
\hline D7 & Mean & 1 & 15.000 & 20.000 & 20.000 & 20.000 & - \\
\hline \multirow[t]{2}{*}{ L1 } & Mean & 4 & 17.750 & 25.000 & 25.000 & 25.000 & \multirow{2}{*}{0.0006} \\
\hline & Std. deviation & & 2.2174 & 0.0000 & 0.0000 & 0.0000 & \\
\hline \multirow[t]{2}{*}{$\mathbf{L 2}$} & Mean & 3 & 18.000 & 27.000 & 27.000 & 27.000 & \multirow{2}{*}{0.0140} \\
\hline & Std. deviation & & 2.6458 & 2.6458 & 2.6458 & 2.6458 & \\
\hline \multirow[t]{2}{*}{$\mathbf{L 3}$} & Mean & 3 & 24.000 & 31.000 & 31.000 & 31.000 & 0.0077 \\
\hline & Std. deviation & & 1.7321 & 1.7321 & 1.7321 & 1.7321 & \\
\hline \multirow{2}{*}{ L4 } & Mean & 2 & 19.000 & 26.500 & 26.500 & 26.500 & 0.0213 \\
\hline & Std. deviation & & 1.4142 & 0.7071 & 0.7071 & 0.7071 & \\
\hline
\end{tabular}

\section{Complication}

3 patients reported with screw breakage without any change in Cobb's angle and AVBH at last follow up.

\section{DISCUSSION}

Thoracolumbar fractures are serious injuries of concern which if left untreated may result in marked morbidity and disability to the patient. The fractures in the spine are reported to be around $6 \%$ approximately amongst the trauma patients, of which around $2.6 \%$ of the patients sustain spinal cord or nerve root level neurological injury. Such fractures are commonly associated with motor and sensory disturbance, bladder and bowel disturbances, erectile dysfunction and deformities like kyphosis or scoliosis. The patients are also prone for bed sores and pulmonary infections due to long term recumbency. ${ }^{11}$

Posterior fixation has become a popular method for the treatment of thoracolumbar burst and compression fractures. For a single-level vertebral fracture, four-screw pedicle fixation has been used in the respective upper and lower vertebrae; however, this cannot achieve satisfactory reduction in the absence of ligament and annulus fibrosis traction. Moreover, the stress concentrated at the pedicle screws leads to a high incidence of loosening and breakage of fixation and loss of vertebral height or kyphosis since there is no anterior support. Transpedicular bone grafting fills the void created in the injured vertebral body providing the much-needed anterior structural stability. ${ }^{8}$ 
We started the study in order to determine the functional outcome of transpedicular bone grafting and pedicle screw fixation in injured vertebrae for the treatment of thoracolumbar fractures using Frankel scale and VAS. We also initiated the study to determine the radiological outcome of transpedicular bone graft and pedicle screw fixation in injured vertebrae for the treatment of thoracolumbar fractures by measuring Cobb's angle and anterior vertebral body height. ${ }^{9,10}$ In our study we also determined the adverse events or complication during intraoperative and post-operative duration.

In our study we enrolled a total of 20 patients, with mean age of 34.7 and standard deviation of 14.77 years. The most common age group in our study was 21-40 years. Perhaps the reason for this could be that the young population are more mobile, hence there is more preponderance in young age. In our study, most of the patients $(n=16)$ were males. Male preponderance was seen perhaps due to the fact that in our country males are more outgoing for work. The age range in another study of Li et al was from 17-65 years. ${ }^{9}$ These results were almost comparable to a study by Uzumcugil et al and Alvine et al in their study found that average age was 31 years, with a male predominance. ${ }^{12,13}$ In our study, the most common mode of injury in our patient was fall from height which is seen in $50 \%$ patients $(n=10)$, followed by road traffic accident and fall of heavy object. Alvine et al noted it as $52 \%$ and Razak et al noted $69 \%$ of the injuries due to fall from height. ${ }^{13,14}$ The single most common vertebrae affected was D12 seen in 5 patients. Otherwise the upper lumbar region accounted for the maximum total number of 10 patients at L1 (4 patients), L2 (3 patients) and L3 (3 patients). In contrast, another study done by Herck et al reported L1 as the most commonly affected vertebrae. ${ }^{15}$

During preoperative period 7 patients were graded as Frankel scale grade E, 4 patients each as Frankel grade $\mathrm{C}$ and D, 3 patients as B and 2 patients as Grade A. During $24^{\text {th }}$ week postoperative period, grade $\mathrm{E}$ was seen in 13 patients, grade $\mathrm{D}$ was seen in 3 patients, $\mathrm{C}$ was seen in 2 patients, $B$ was seen in 1 patient and $A$ was seen in 1 patient. There was statistically significant difference between the Frankel scale grading of preoperative and $6^{\text {th }}$ week postoperative period. But there was no statistically significant difference between the $6^{\text {th }}$ week postoperative and 24th postoperative week Frankel scale grading i.e. whatever improvement in neurological status happened, it happened significantly during the first six weeks only. In another study, they show spinal nervous function recovered I to II grade, 1 case was grade $\mathrm{C}, 3$ cases were grade D, 52 cases were grade $\mathrm{E}$ at final follow up. ${ }^{16}$

The mean value of the VAS at baseline was 9.8, which decreases significantly to 6.8 at 6 weeks, and the decline was continuously seen at 12 weeks with value of VAS score to 3 and at $24^{\text {th }}$ week mean VAS score decreased to a very low level of 0.75 . In this study $45 \%(n=9)$ of the patients had no pain, $35 \%(n=7)$ had occasional minimal pain with no need for medication, $20 \%(n=4)$ had moderate pain with occasional need for medication. In another study done by $\mathrm{Li}$ et al noted significant reduction of pain post operatively. ${ }^{9}$

In our study, the baseline mean value of Cobb's angle was 12 degrees. At 6, 12 and 24 weeks, majority of patients $(n=7)$ had a Cobb's angle of 25 degrees. In our study, Cobb's angle was improved significantly from the baseline value of 12 degrees to 22.05 degrees at $6^{\text {th }}$ week and this was maintained till $24^{\text {th }}$ weeks. That is, there was a significant improvement seen in the majority of the patients in terms of decrease in kyphosis. This change in Cobb's angle was found to be highly significant with fractures of the lumbar vertebra. In another study mean Cobb's angle improved from +7.16 degrees to -5.48 degrees with a mean loss of correction of 1.00 degrees at two years. ${ }^{15}$ A study done by Dai et al show Cobb's angle was restored from $(32.80 \pm 8.20)$ degrees to $(4.20 \pm 1.60)$ degrees. ${ }^{17}$

Most of the patient $(\mathrm{n}=4)$ had AVBH at $12 \mathrm{~mm}$ or $13 \mathrm{~mm}$ at baseline. There was seen an improvement of AVBH at 6,12 and 24 weeks in the majority of patients, 4 patients had AVBH of $22 \mathrm{~mm}$. In our study, mean anterior vertebral body height was seen to improve from baseline value of $20.1 \mathrm{~mm}$ to $27.25 \mathrm{~mm}$ at $6^{\text {th }}$ week and this improvement persisted till $24^{\text {th }}$ weeks. In another study, they concluded that reinforcement of short-segment fixation with transpedicular intracorporeal grafting can effectively restore vertebral body height and prevent loss of correction for patients with thoracolumbar burst fractures. ${ }^{18} \mathrm{~A}$ study done by Dai et al show the anterior edge height of the fractured vertebrae body was restored from $(21.00 \pm 12.00) \%$ to $(95.00 \pm 4.20) \% .^{17}$

In our study, eighty five percent of the study group $(n=17)$ did not show any complications. $15 \%$ patients $(n=3)$ reported with screw breakage at the last follow up, but without any change in Cobb's angle and AVBH. Among all the subjects $30 \%(n=6)$ of the patients returned to their previous work or physically challenging job, $40 \%$ $(\mathrm{n}=8)$ were able to return to previous employment with some restriction, $20 \%(n=4)$ of the patients were unable to return to their previous employment but worked for full time in their new employment and $10 \%(n=2)$ of the patients were unable to return to their full time work.

\section{CONCLUSION}

There is a statistically significant restoration of vertebral body height, Cobb's angle and decrease in visual analogue scale right from the first follow up which was maintained till the last follow up. Neurological recovery was seen significantly when all cases with neurological deficits were clubbed together, except for one patient with complete neurological deficit. Complications were comparable with other studies. This study demonstrated that this technique effectively corrects deformities, restores anterior vertebral body height, prevents early 
implant failure, and provides satisfactory clinical results. Therefore, it is reasonable to conclude that transpedicular bone grafting provide good support to the anterior vertebral column, and is a good surgical technique to be used along with pedicle screw fixation in certain types of thoracolumbar vertebral fractures.

Funding: No funding sources

Conflict of interest: None declared

Ethical approval: The study was approved by the institutional ethics committee

\section{REFERENCES}

1. Lukas R, Suchomel P, Sram J. Surgical treatment of thoracolumbar spine fractures. Colunacolumna. 2006;5(2):84-89.

2. Kraemer WJ, Schemitsch EH, Lever J, McBroom RJ, McKee MD, Waddell JP. Functional outcome of thoracolumbar burst fractures without neurological deficit. J Orthop Trauma. 1996;10(8):541-4.

3. Riggins RS, Kraus JF. The risk of neurological damage with fractures of the vertebrae. J Trauma. 1977:126-133.

4. Benson DR, Keenen TL. Evaluation and Treatment of Trauma to the Vertebral Column. J Bone Joint Surg. 1990;39:577-88.

5. Blick EM. Source of orthopaedics. Baltimore: Lippincott Williams and Wilkins; 1948; 236-238.

6. Jones WR. Fractures and Joint Injuries; Ed. J.B. Wilson, Edinburgh: Churchill Livingstone; 1982: 789-792.

7. Avila JM, Garcia OV, Soto OR. Thoracolumbar spine burstfactor. Screw fixation. Acta Ortop Mex. 2013;27(3):170-6.

8. Li Q, Liu Y, Chu Z, Chen J, Chen M. Treatment of thoracolumbar fractures with transpedicular intervertebral bone graft and pedicle screws fixation in injured vertebrae. Zhongguo Xiu Fu Chong Jian Wai Ke Za Zhi. 2011;25(8):956-9.

9. Li GM, Tang DZ. Short-segment posterior pedicle screw combined with vertebral arch bone grafting for thoracolumbar burst fractures. Zhongguo Gu Shang. 2015;28(1):8-11.

10. Li T, Xiao R, Guan Q, Wang M, Dong C. Improved method of treating thoracolumbar burst fracture by posterior pedicle fixation and grafting through injured vertebrae. Zhongguo Xiu Fu Chong Jian Wai Ke Za Zhi. 2012;26(5):546-9.

11. Burney RE, Maio RF, Maynard F. Incidence, characteristics, and outcome of spinal cord injury at trauma centres in North America. Arch Surg. 1993;128(5):596-9.

12. Uzumcugil O, Dogan A, Yetis M, Yalcinkaya, Caniklioglu M. Results of 'Two above - one below approach' with intermediate screws at the fracture site in the surgical treatment of thoracolumbar burst fractures. Kobe J Med Sci. 2010;56(2):67-78.

13. Alvine GF, Swain JM, Asher MA, Burton DC. Treatment of thoracolumbar burst fractures with variable screw placement or Isola instrumentation and arthrodesis: case series and literature review. J Spinal Disord Tech. 2004;17(4):251-64.

14. Razak M, Mahmud MM, Hyzan MY, Omar A. Short segment posterior instrumentation, reduction and fusion of unstable thoracolumbar burst fractures: a review of 26 cases. Med J Malaysia. 2000;55:9-13.

15. Herck VB, Leirs G, Loon VJ. Transpedicular bone grafting as a supplement to posterior pedicle screw instrumentation in thoracolumbar burst fractures. Acta Orthop Belg. 2009;75(6):815-21.

16. Zeng ZY, Wu P, Zhang JQ, Tang HC, Song YX, Yan $\mathrm{WF}$, et al. Injury characteristics and surgical treatment of lower lumbar vertebral burst fractures. Zhongguo GU Shang. 2014;27(2):112-7.

17. Dai FQ, Du Y, Luo LX, Zhang YQ. Treatment of serious burst thoracolumbar fracture with posterior pedicle screw fixation, transpedicular bone grafting and vertebral canaloplasty. Zhongguo Gu Shang. 2010;23(7):504-6.

18. Li DP, Yang HL, Huang YH, Xu XF, Sun TC, Hu L. Transpedicular intracorporeal grafting for patients with thoracolumbar burst fractures. Saudi Med J. 2014;35(1):50-5.

Cite this article as: Singh $\mathrm{H}$, Rampurwala AJ, Rudani TS, Gandhi MP. Outcome of pedicle screw fixation with transpedicular bone grafting in fracture of thoracolumbar vertebrae. Int J Res Orthop 2020;6:587-92. 